\title{
Threshold sediment flux for the formation of river deltas in Hainan Island, southern China
}

\author{
LI Gaocong ${ }^{1}$, ZHOU Liang ${ }^{2}$, QI Yali ${ }^{1,3}$, *GAO Shu²
}

1. Collaborative Innovation Center of South China Sea Studies, Nanjing University, Nanjing 210023, China;

2. State Key Laboratory for Estuarine and Coastal Research, East China Normal University, Shanghai 200062, China;

3. College of Electronics and Information Engineering, Guangdong Ocean University, Zhanjiang 524088, Guangdong, China

\begin{abstract}
The knowledge of geomorphological evolution from an estuary to a river delta is necessary to form the formulation of comprehensive land-ocean interaction management strategies. In this study, the dominant factor controlling the geomorphological variability and the threshold sediment flux (TSF) to form a river delta in Hainan Island, southern China, including accommodation space, sediment supply, and reworking forces, was investigated by the method of big data analytics. The results indicated the 25 estuaries in consideration can be divided into three geographical groups, i.e. the multi-factors-controlled northern mixed estuaries, wave-dominated western estuaries with river deltas, and typhoon-dominated eastern coastal lagoon estuaries. For alluvial plain (AP) estuaries, the order of magnitude of TSFs is the smallest $\left(10^{1} \mathrm{kt}^{-} \cdot \mathrm{rr}^{-1}\right)$, for barrier-lagoon (BL) ones is the highest $\left(>10^{2} \mathrm{kt} \cdot \mathrm{yr}^{-1}\right)$, and for drowned valley (DV) ones is moderate $\left(10^{2} \mathrm{kt}^{-} \mathrm{yr}^{-1}\right)$. The river deltas associated with DV systems should be relatively large, and those related to BLs should be small, with the AP deltas being between the above mentioned types. The present study provides a technique to evaluate the role played by TSF for the formation of river deltas in micro-tidal and wave-dominated and typhoon-influenced coastal environments.
\end{abstract}

Keywords: estuarine geomorphology; dominant factor; typhoon processes; threshold sediment flux; river delta; Hainan Island

\section{Introduction}

River deltas are important interfaces between continents and oceans, playing a role of both "driver" and "recorders" for natural and anthropogenic environment changes (Bianchi and Allison, 2009; Gao and Collins, 2014; Schmidt, 2015). Fluvial sediment supply is the principal source for such systems with respect to the source-to-sink mechanisms (Bates, 1953; Wright, 1977). The occurrence of a river delta will not happen as the amount of sediment

Received: 2017-08-14 Accepted: 2017-12-15

Foundation: National Natural Science Foundation of China, No.41530962, No.41706096; This study also supports in part by the China Scholarship Council, No.201606190151

Author: Li Gaocong (1987-), PhD Candidate, specialized in estuarine and coastal sciences. E-mail: ligaocong2013@163.com

"Corresponding author: Gao Shu (1956-), Professor, E-mail: sgao@sklec.ecnu.edu.cn 
available is below a critical value or threshold (Sloss, 1963; Vail et al., 1977; Gao and Collins, 2014). Long-term global climate has changed catchment-estuarine systems and, nowadays, worldwide river deltas are not only under dramatic threat from sediment starvation, but also suffer from river flooding, natural and man-made subsidence, sea-level rise, storm surges and coastal erosion (Blum and Roberts, 2009; Foufoula-Georgiou, 2013; Zhong et al., 2014; Han et al., 2015). Thus, any knowledge of the threshold sediment flux for the transition from an estuary to a river delta becomes important to formulate comprehensive land-ocean interaction management strategies (Stanley and Warne, 1994; Syvitski and Milliman, 2007; Giosan et al., 2014). However, although the concept of threshold sediment flux for the formation of a river delta was proposed several decades ago, little attention has been paid to the quantifying of this variable.

Regarding the above-mentioned situations, the estuaries and river deltas along the coastlines of Hainan Island, southern China, represent typical examples. In terms of the magnitude of sediment supply, the total flux has been estimated to be around $4 \mathrm{Mt} \cdot \mathrm{yr}^{-1}$ (CEH, 1999), which is a very small value as compared to that of Taiwan Island (Chen et al., 1992) and islands in East Indies (Milliman et al., 1999; Milliman and Farnsworth, 2013). Significant geomorphological variability of estuaries, however, can be identified along the coastal Hainan (Gao et al., 2016; Li et al., 2016). Apparently, such a variability is related to factors of the sea-level changes, morphological/bathymetric characteristics, terrestrial sediment supply, and hydrodynamic forcing. Although previous studies have dealt with some of the factors, e.g., geological background (Wang et al., 1983; Wang, 2006), history of sea level changes (Zhang and Liu, 1987; Ma et al., 2003), waves and tidal range (Wang et al., 1983; Wang et al., 2001), typhoon influence incidences (Tu et al., 2016; Zhou et al., 2017), the vulnerability of coasts (Wang et al., 2017) and sedimentary records interpretation (Gao et al., 2016), there is a lack of systematic investigation into the factor of sediment flux of different rivers.

In the present study, a dataset of 25 estuaries was established by the method of big data analytics, including factors of estuarine original topography, history of sea level changes, catchment basin elevation maximum $\left(h_{\max }\right)$ and area $(A)$, hypsometry integral $(H I)$, sediment flux $\left(Q_{s}\right)$, average wave height, average tidal range, intensive typhoon events, and estuarine geomorphology. On such a basis, the dominant factor influencing estuarine geomorphological variability and the threshold sediment flux (TSF) for the formation of river deltas in coastal Hainan during the Holocene were analyzed.

\section{Study area}

Located in southern China and northwestern part of the South China Sea (Figure 1a), Hainan Island is the second largest island in China, with a surface area of $35.4 \times 10^{3} \mathrm{~km}^{2}$. Its landscape is characterized by mountains in the central part, and hills and highly indented promontory-embayment coastlines in the coastal areas. The highest mountain is the Mt. Wuzhishan, reaching an elevation of $1867 \mathrm{~m}$ above sea level. The mountains and hills are mostly composed of Palaeozoic metamorphic and sedimentary rocks, intruded by Paleozoic and Mesozoic granites, and the outcrop rocks of northern Hainan is mostly composed of Cenozoic to Holocene volcanic, basaltic rocks (Wang and Zhou, 1990; Wang et al., 2001). 


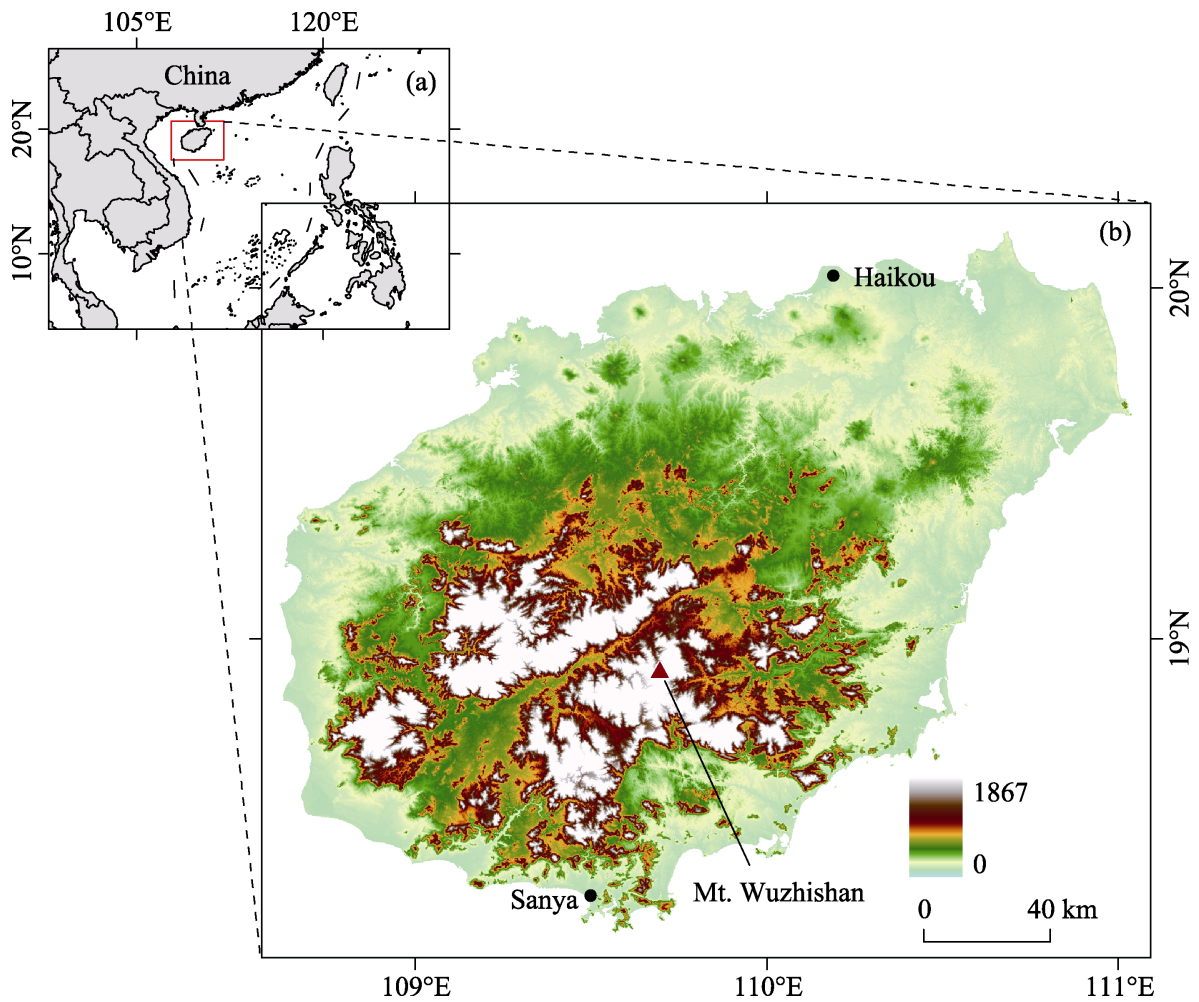

Figure 1 Location (a) and digital elevation model (b) of the study area

The climate is dominated by tropical monsoons, with northeast winds in winter and southwest winds in summer (Zhang et al., 2013). The annual average temperature is within the range of $22.8-25.8^{\circ} \mathrm{C}$ (SBHP, 1994-2011). The tide in this area is diurnal and in a microtidal environment, with a range of 0.69-1.89 m; NE wave prevails during winter, SE and SW waves prevail during summer (Wang et al., 1983; Wang et al., 2001). Typhoons are frequent in the summer rainy season and they derive both from the west Pacific Ocean and from the South China Sea (CDCCBC, 1999; STI, 2006).

\section{Methods}

\subsection{Data sources}

In the present study, the first step is to carry out catchment basin analysis on the ArcGis 9.3, using a $90 \mathrm{~m}$ resolution Digital Elevation Model (DEM) of Hainan Island downloaded from the Geospatial Data Cloud (http://www.gscloud.cn) (Figure 1b). Subsequently, the variables of catchment basin area $(A)$, elevation maximum $\left(H_{\max }\right)$, mean $\left(H_{\text {mean }}\right)$, and minimum $\left(H_{\min }\right)$ could be obtained (Li et al., 2016). In terms of spatial resolution, the highest relative error of every pixel point is $45 \mathrm{~m}$. For the calculation of estuarine sediment flux, two parameters, e.g. elevation maximum and area were used. Since their units are in $\mathrm{km}$ and $\mathrm{km}^{2}$, which are two orders of magnitude higher than the data resolution, it is assumed in this study that the impact of error related to the spatial resolution on sediment flux results should be small. Combined with estuarine remote sensing imagines on the Google Earth Pro, 25 rivers were cho- 
sen as the study estuaries subjectively. These rivers are located more or less uniformly around the Hainan coastlines with easily recognizable estuarine geomorphology, with their total catchment basin area accounts for $80.78 \%$ of Hainan Island (Figure 2a).

Data of other factors were collected based on the big data analytical method by making full use of previous research results (Cukier and Viktor, 2013; Hampton et al., 2013). The original topography of estuaries is consulted from the studies of Wang et al. (1983) and Yuan et al. (2006). The history of sea level changes of Hainan Island since the mid-Holocene were collected from the studies of Luo (1986), Zhang and Liu (1987), Li (1996), Wang (1999), and Ma et al. (2003). The observed average wave height (Figure 2b) and average tidal range (Figure 2c) pertain to the studies of Wang et al. (1983) and Wang et al. (2001). The number of times influenced intensively by typhoon from 1949 to 2014 is based on Tu et al. (2016) (Figure 2d).
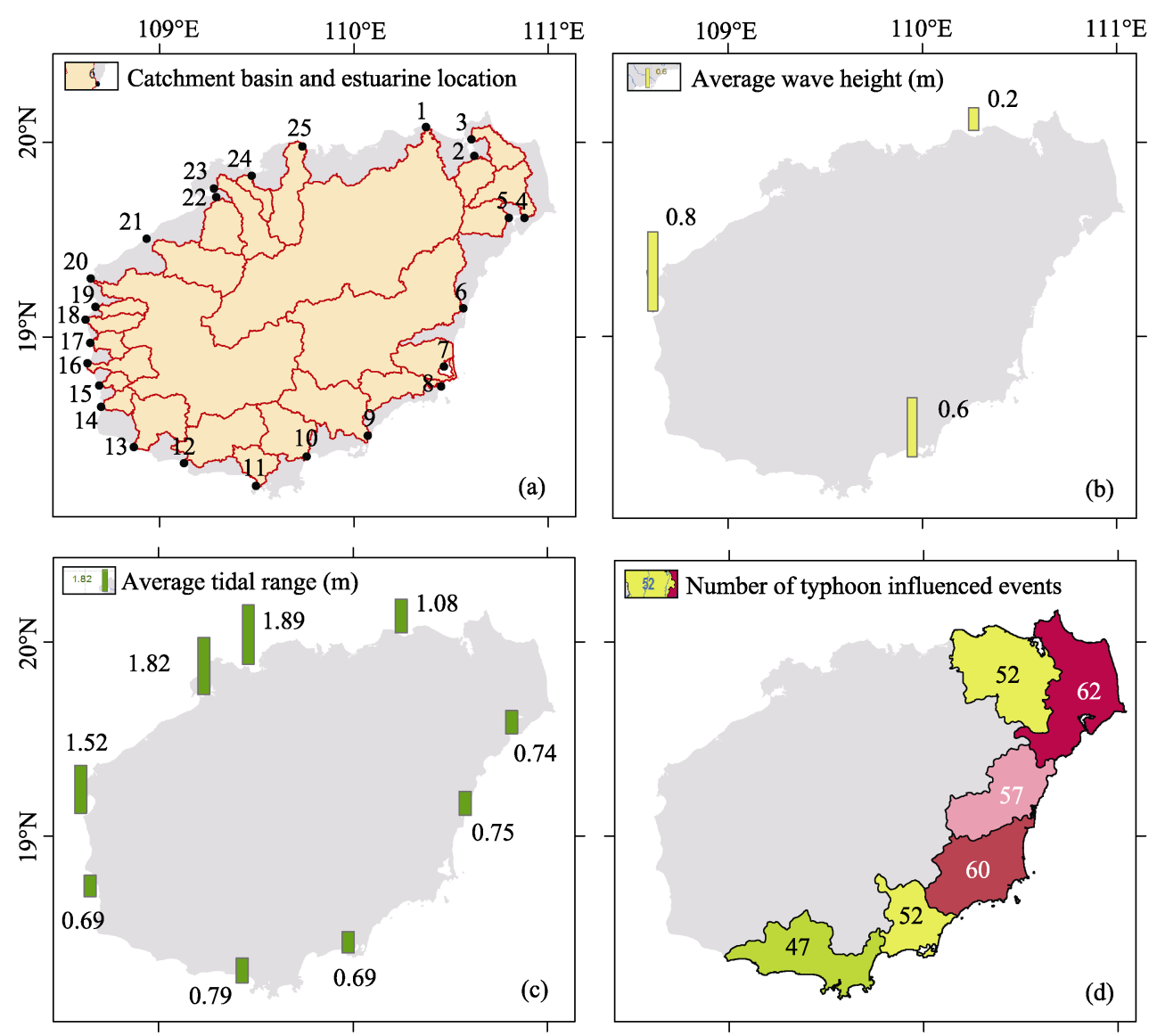

Figure 2 Estuaries in consideration (a), average wave height (b), average tidal range (c), and the number of intensive typhoons (d) from 1949 to 2014

\subsection{Analytical methods}

\subsubsection{Accommodation space identification}

The accommodation space for estuarine sedimentation is mainly determined by factors of the estuarine original topography and sea level changes (Sloss, 1963; Vail et al., 1977; Gao 
and Collins, 2014). For the estuaries of Hainan Island, their original topography includes alluvial valley (AV), pluvial-alluvial terrace (PAT), and structural valley (SV). With the sea level changes during the mid-Holocene, the accommodation space of these estuaries transform to three categories, e.g. alluvial plain (AP), barrier-lagoon (BL), and drowned valley (DV).

\subsubsection{Sediment flux estimation}

The BQART formula (Syvitski and Milliman, 2007) is generally used to compute fluvial sediment flux $\left(Q_{s}\right)$, and specific cases can be found in studies of Kettner et al. (2010) and Nienhuis et al. (2015). This formula estimates the $Q_{s}$ based on geomorphic and tectonic influences (basin area and relief), geography (temperature, runoff), geology (lithology, ice cover), and human activities (reservoir trapping, soil erosion):

$$
\begin{gathered}
Q=0.075 A^{0.8} \\
Q_{S}=\omega B Q^{0.31} A^{0.5} R T
\end{gathered}
$$

where $Q$ is fluvial discharge $\left(\mathrm{m}^{3} \cdot \mathrm{s}^{-1}\right), A$ is drainage area $\left(\mathrm{km}^{2}\right), \omega=0.0006$ is a constant of proportionality. $B=I L\left(1-T_{E}\right) E_{h}$ accounts for geological and land use factors; $I$ is glacier erosion factor ( 1 in this case); $L$ is an average basin-wide lithology factor; $T_{E}$ and $E_{h}$ account respectively for the trapping efficiency of lakes and man-made reservoirs and human-influenced soil erosion factor which was assumed to cancel out (Syvitski and Milliman, 2007; Nienhuis et al., 2015). Because the study area mainly composed of granite in basaltic lithology (Wang et al., 1991), this study assigned $L=1$ for the study basins. $R$ is the maximum relief $(\mathrm{km})$ and $T=23.5$ is the basin average temperature. At last, those predicted values were corrected by the gauging station records from the studies of Yang et al. (2013).

\subsubsection{Hypsometry integral analysis}

In terms of the geomorphological evolution stage, sediment flux discharges from catchment basin are relatively smaller, larger, and smaller in relation to the 'young', 'mature', and 'old' stages, respectively (Li et al., 2016). The Hypsometry Integral (HI) is generally used to infer the stage of geomorphic development of a drainage basin (Strahler, 1952). Convex hypsometric curves characterize relatively 'young' and weakly eroded regions $(H I>0.6)$, S-shaped curves characterize moderately eroded regions $(0.35<H I<0.6)$, and concave curves characterize relatively 'old' and highly eroded regions $(H I<0.35)$. The value of $H I$ can be estimated by

$$
H I=\left(H_{\text {mean }}-H_{\min }\right) /\left(H_{\max }-H_{\min }\right)
$$

where $H_{\text {mean }}$ and $\left(H_{\max }-H_{\min }\right)$ are the mean elevation and the elevation drop of the basin, respectively (Pike and Wilson, 1971).

\subsubsection{Bed reworking forces analysis}

In this study, three factors, including the average wave height, average tidal range, and the number of intensive typhoon events, were regarded as the main reworking forces for the sediment deposition in estuarine regions. The data of observed average wave height and average tidal range, collected from the studies of Wang et al. (1983) and Wang et al. (2001), was used to interpolate values for each estuary in consideration, according to the principle of Kriging and estuarine coordinates. 


\subsubsection{Estuarine geomorphological classification}

To determine the categories of the estuaries, the criterion of morphogenetic classification of estuaries given by Perillo (1995) was used. It consists of primary and secondary categories. The former includes former river valleys, former glacial valleys, river-dominated, and structural subcategories, and the latter refers to coastal lagoon estuary which includes choked, restricted, and leaky subcategories. In this study, the estuarine geomorphological classifications were determined by visual interpretation method with respect to their accommodation space and satellite imagines characteristics.

\subsubsection{Threshold sediment flux analysis}

In this study, the term "threshold sediment flux (TSF)" refers to the threshold of fluvial sediment flux for the formation of a river delta during the Holocene. Only when the sediment flux of a river is greater than the TSF, can a river delta be formed in its estuarine region (Gao and Collins, 2014). Its value generally depends on the accommodation space and bed reworking forces of the estuarine area. Figure 3 illustrates the procedures to determine the order of magnitude of TSF, for which factors of the estuarine geomorphological classification, accommodation space, and sediment supply are all taken into account. First the type of accommodation space of the given estuary is determined, then to determine whether or not the estuary is a delta front estuary, after that, to define whether or not the $Q_{s}$ of the catchment basin is larger than the TSF.

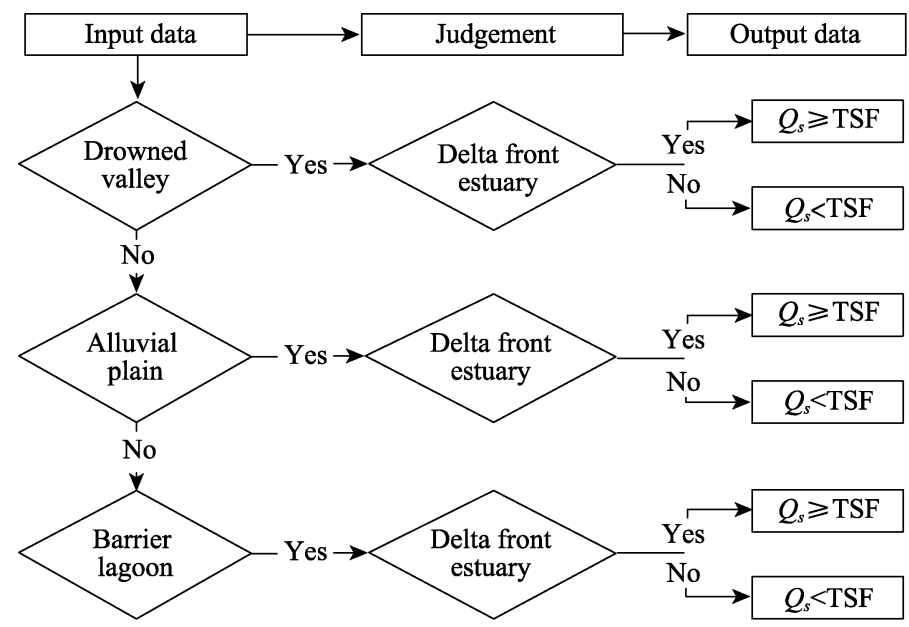

Figure 3 Flow chart for the determination of the order of magnitude of TSF

\section{Results}

\subsection{Accommodation space}

In terms of estuarine original topography, either SVs or AVs characterize the base of the topography of the north and west coastal Hainan, and the PATs dominated in the west coast (Wang, 1983; Yuan et al., 2006) (Table 1). Since the Last Glacial Period, sea level rose to 4 $\mathrm{m}$ above the present position in ca. 6800 to 5800 a BP (Ma et al., 2003); since then, two cycles of rise-drop of sea level occurred, with a magnitude of 4-6 m (Zhang and Liu, 1987). 
The sea level gradually stabilized as the present position in the last 2000 years, and at present, the level is rising slightly caused by global warming (Wang, 1999). With the sea level changes, sediments from the adjacent continental shelf were transported shoreward, and gradually combined the Late Pleistocene pluvial-alluvial terraces and erosion platforms or the hills ( $\mathrm{Li}, 1986)$. As a result, many barrier-lagoon systems were formed in the eastern Hainan coastlines, with barriers in width of 1-2 km, in length of 10-30 km and in height of 20-30 m (Luo, 1986). Meanwhile, the accommodation space of those SVs or AVs estuaries have transformed to drowned valley (DV) and alluvial plain (AP) estuaries.

\subsection{Estuarine sediment flux}

Similar to the characteristic of basins' areas, the Nandu, Changhua, and Wanquan rivers have the largest $Q_{s}$, with annual sediment discharge of 9.20, 5.99 and 7.07 Mt, respectively. These predicted values, however, are one order of magnitude higher than that of gauging station records (e.g. Yang et al., 2013). This study used $\alpha=0.1$ as the correction coefficient for $Q_{s}$. Consequently, the annual sediment flux of the above three rivers is 920,599 and $707 \mathrm{kt}$, respectively.

The modified $Q_{s}$ of these three rivers is greater than other rivers considerably, of which only 5 rivers have the order of magnitude of $100-200 \mathrm{kt} \cdot \mathrm{yr}^{-1}$ for $Q_{s}$, and the other 17 rivers are in order of magnitude of $\sim 10-100 \mathrm{kt} \cdot \mathrm{yr}^{-1}$ (Table 1). The total $Q_{s}$ of the basins in consideration is $\sim 3.50 \mathrm{Mt} \cdot \mathrm{yr}^{-1}$. When the rest basins are being consideration, the total $Q_{s}$ for Hainan Island is supposed to around $4 \mathrm{Mt}^{\cdot} \mathrm{yr}^{-1}$, a value in accordance with the value of previously studied by the Committee of Encyclopedia of Hainan (1999). Thus, the correction coefficient ( $\alpha=0.1$ ) was considered to be valid which can be used in subsequent analysis.

All basins in consideration have hypsometric curves in shape of concave (Figure 4). On average, the $H I$ values is 0.18 , ranging from 0.07 to 0.28 (Table 1 ). Both concave curves and low $H I$ values indicate the old geomorphological evolution stage of the study basins (Strahler, 1952; Li et al., 2016). In addition, the $H I$ value is relatively larger in the western and and southern basins than eastern and northern basins.

\subsection{Characteristics of rework- ing forces}

Figures 2b, 2c, 2d and Table 1 show that, the three reworking forces have a strong regional signature. The average wave height tends to decrease from $0.8 \mathrm{~m}$ in western coast to approximately 0.2 $\mathrm{m}$ in the north-eastern coast (Wang et al., 1983; Wang et al., 2001). The average tidal range decreases from more than $1.89 \mathrm{~m}$ in northeastern Hainan to approximately $0.69 \mathrm{~m}$ in southeastern Hainan

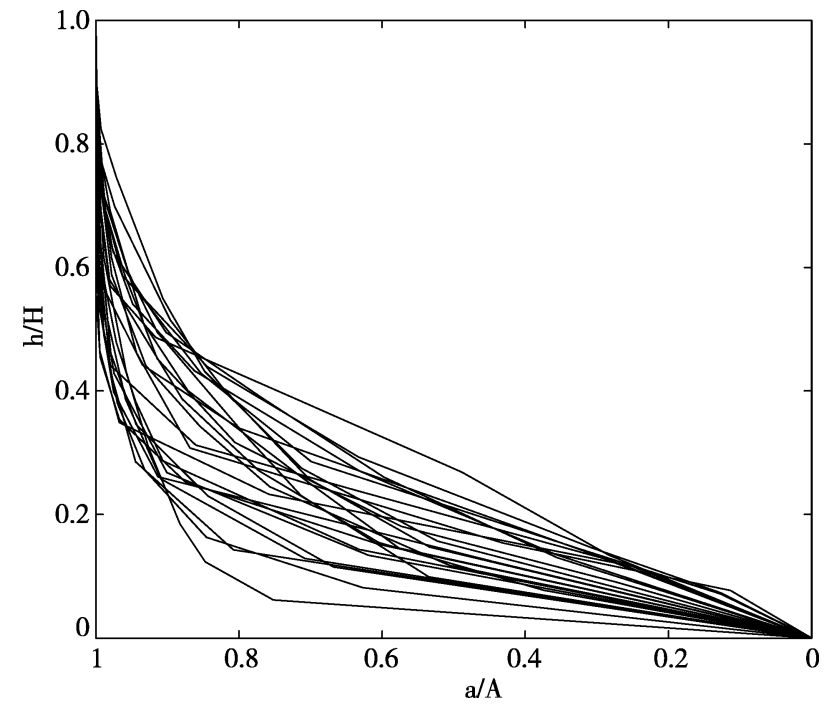

Figure 4 Concave normalized hypsometric curves of the study basins 
(Wang et al., 1983). In addition, typhoon process influenced estuaries on eastern coast significantly, and they occur with an average frequency of 8 events $\mathrm{yr}^{-1}$ over the last five decades (CDCCBC, 1999; STI, 2006; Tu et al., 2016). Thus, in terms of the dominant bed reworking force, wave dominates the western coast, typhoon dominates the eastern coast, and tide dominates the northern coast.

\subsection{Estuarine geomorphological identification}

Two categories and four subcategories of estuarine types can be identified from the 25 estuaries in Hainan coasts (Table 1). The first category is primary estuary and mostly located in the northern, western and southern coasts, including tidal river, delta front, and structural subcategories. The Yangqiao and Wenlan estuaries belong to tidal river subcategory, with increasing width of the river channel in the seaward direction. Except for the Nandu estuary in the northern part of Hainan Island, the subcategory of the delta front estuary is most common in the southwestern coast. The structural estuary is common on the northern coast, including Chun, Beimen, Nanyang, and Zhuxi rivers. The last subcategory is choked estuary and most common in the eastern and southeastern coasts (Figure 5).
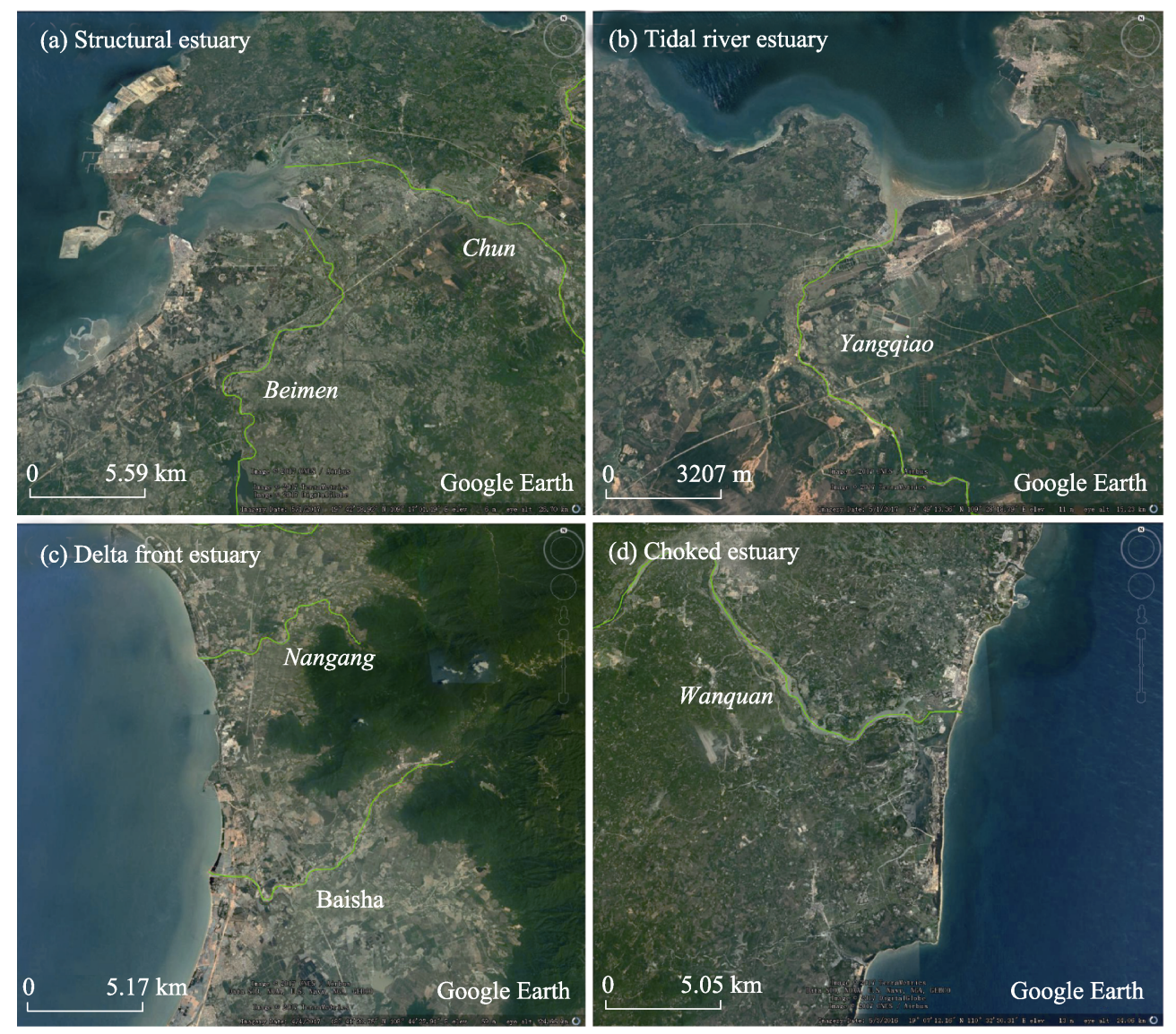

Figure 5 Estuarine remote sensing imagines: (a) structural estuary; (b) tidal river estuary; (c) delta front estuary; (d) choked estuary 


\subsection{Threshold sediment flux}

In terms of the accommodation space, Hainan estuaries can be divided into DV, BL, and AP categories. For the estuaries of DV category, when the sediment supply is ranged from 5 to $62 \mathrm{kt}^{\cdot} \mathrm{yr}^{-1}$, the estuarine geomorphology belongs to the structural estuary. As the supply increases to 707 and $920 \mathrm{kt} \cdot \mathrm{yr}^{-1}$, the geomorphology, however, belongs to delta front estuary. For the BL category, all estuaries belong to the choked subcategory, with a large range from 9 to $599 \mathrm{kt} \cdot \mathrm{yr}^{-1}$. For the AP category, the geomorphology belongs to delta front estuary when the supply is ranged from 9 to $160 \mathrm{kt} \cdot \mathrm{yr}^{-1}$, except for the two tidal river estuaries in the northern coast. The latter is characterized by a relatively small average wave height $(0.3 \mathrm{~m})$ and a relatively large average tidal range $(1.63-1.89 \mathrm{~m})$ compared with the former. Thus, in terms of TSF to form a river delta in coastal Hainan, the order of magnitude for AP estuaries is $10^{1} \mathrm{kt} \cdot \mathrm{yr}^{-1}$, for DV ones is $10^{2} \mathrm{kt} \cdot \mathrm{yr}^{-1}$, and for BL ones should be larger than $10^{2} \mathrm{kt} \cdot \mathrm{yr}^{-1}$.

\section{Discussion}

\subsection{Dominant factor controlling the estuarine geomorphological variability}

In terms of morphogenetic classification, this study indicated significant variation among the estuaries in the Hainan coasts. The primary estuaries include tidal river, delta front and structural subcategories located in the northern and western coasts; secondary estuaries (choked estuary) in the eastern coast (Figure 6). Enhanced knowledge of dominant factor controlling the evolution of estuaries in coastal Hainan during the Holocene is important for understanding the variability of estuarine geomorphology.

The accommodation space, terrestrial sediment supply, and hydrodynamic forcing are generally considered as the three main factors influencing the geomorphological evolution of estuaries (Dyer, 1995; Gao and Collins, 2014). Apparently, the characteristic of estuarine accommodation space controlled the first-order variation of estuaries, while the factors of sediment supply and hydrodynamic forces controlled their secondary-order variation. Although the sediment fluxes of northern and eastern rivers are larger than that of western rivers, no river delta has developed in these areas (except for the Nandu River which characterized by a relative large sediment flux), while many wave-dominated river deltas have formed in the western coast. The average wave height is larger on the western coast than that on the northern and eastern coasts, and the tide range is larger on the northern coast than the southern coast (Wang et al., 1983). In addition, typhoon processes affect sediment erosion and accretion of eastern coast considerably, because of their strong winds, high waves, strong currents, and heavy rains (Tu et al., 2016; Huang, 2017).

Therefore, the dominant factor controlling the estuarine geomorphological variability on coastal Hainan have a strong regional signature. Waves dominate the western delta frontal estuarine hydrodynamic environment, and tide, sediment supply, and original topography dominate the northern mixed estuarine environment, and typhoon dominate the eastern coastal lagoon estuarine environment. As such, the estuaries in consideration can be divided into three geographical groups, i.e. the multifactor-controlled northern mixed estuaries, wave-dominated western estuaries with deltas, and typhoon-dominated eastern coastal lagoon estuaries (Figure 6). In the future, additional research work should focus on the observations and numerical modeling of alongshore transport either induced by waves and typhoon events to better 
understand the sediment budget around estuaries on coastal Hainan.

\subsection{Threshold sediment flux for the formation of river deltas}

The present estuarine geomorphology is the comprehensive product of accommodation space, fluvial sediment supply and estuarine hydrodynamic forces since the high sea level period during the Holocene (Inman and Nordstrom, 1971; Stanley and Warne, 1994). The geomorphological variability of estuaries in coastal Hainan

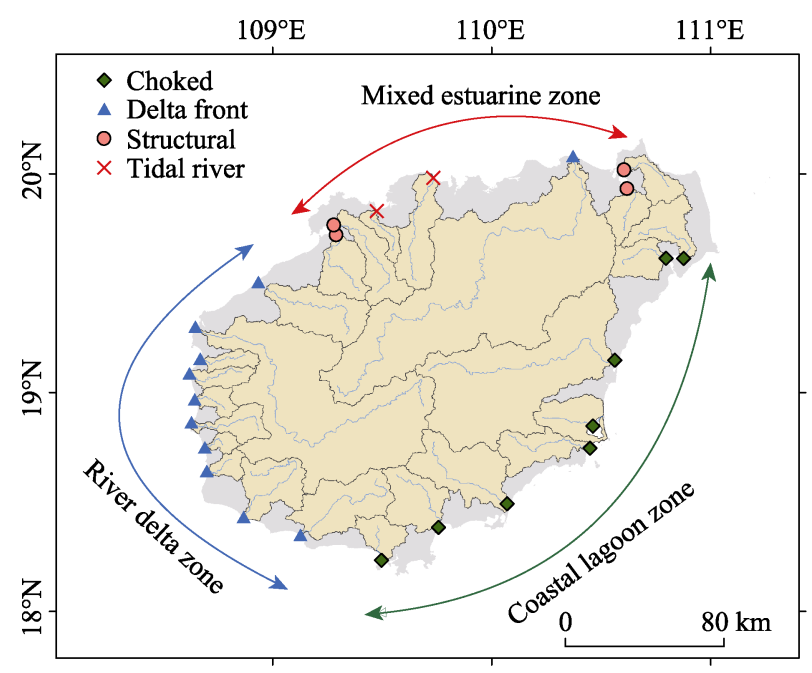

Figure 6 Geomorphological classification of the studied estuaries arises an interesting question related to the geomorphological evolution from an estuary to a river delta, i.e., whether or not there is a threshold flux of fluvial sediment for forming a river delta.. Whether or not the fluvial sediment will settle down in an estuary and eventually contribute to the delta formation depends upon many factors, such as river flow patterns in an estuary (Bates, 1953), gravitational circulation (Dyer, 1995), tidal pumping (Dyer, 1995; Yu et al., 2014), flocculation processes (Eisma, 1986), wave processes (Aston and Giosan, 2011; Nienhuis et al., 2015), typhoon (Huang, 2017), and water depth (Gao, 2007). Although in situ observations could be used to obtained precise sediment budgets of the estuaries, they cost a great deal of time and money; further, those processes occurred in past cannot be obtain by observation. Thus, it is meaningful to propose a practical method by using various existing data to determine the TSF for the studies of estuarine geomorphological evolution.

The present study provides a typical example to evaluate the role played by TSF for the formation of river deltas in coastal Hainan by using many existing data, including factors of accommodation space, sediment supply, and bed reworking forcing. The results show that the TSF is in close contact with the type of accommodation space. In order to form a river delta in coastal Hainan, the order of magnitude of TSF for AP estuaries $\left(10^{1} \mathrm{kt}^{\cdot} \mathrm{yr}^{-1}\right)$ is the smallest, for $\mathrm{BL}$ ones is the largest $\left(>10^{2} \mathrm{kt}^{\cdot} \mathrm{yr}^{-1}\right)$, and for DV ones is in between $\left(10^{2}\right.$ $\left.\mathrm{kt} \cdot \mathrm{yr}^{-1}\right)$. For the structural estuaries in northern coast and choked estuaries in the eastern coast, more fluvial sediments, first of all, are needed to fill the large accommodation of incised valleys and lagoons than that of those alluvial plain estuaries. Although the filling process of many southern lagoons has been completed, these lagoons, however, also failed to form delta frontal deposition. A reasonable explanation for this is that alongshore sediment transport and reworking induced by typhoon processes is so strong to inhibit enough fluvial sediments to settle down. In addition, the eastern coastlines show a spiral plan shape, representing an equilibrium state of geomorphological evolution (Davis and Hayes, 1984). Moreover, the catchment basins in consideration are all at an 'old' geomorphological evolution stage, of which the sediment discharge flux should be relatively smaller than 'mature' stage in their life-cycle (Li et al., 2016). Therefore, although the $Q_{s}$ values of the eastern rivers are larger than that of western rivers, river delta will be only poorly developed over a long period of time. 


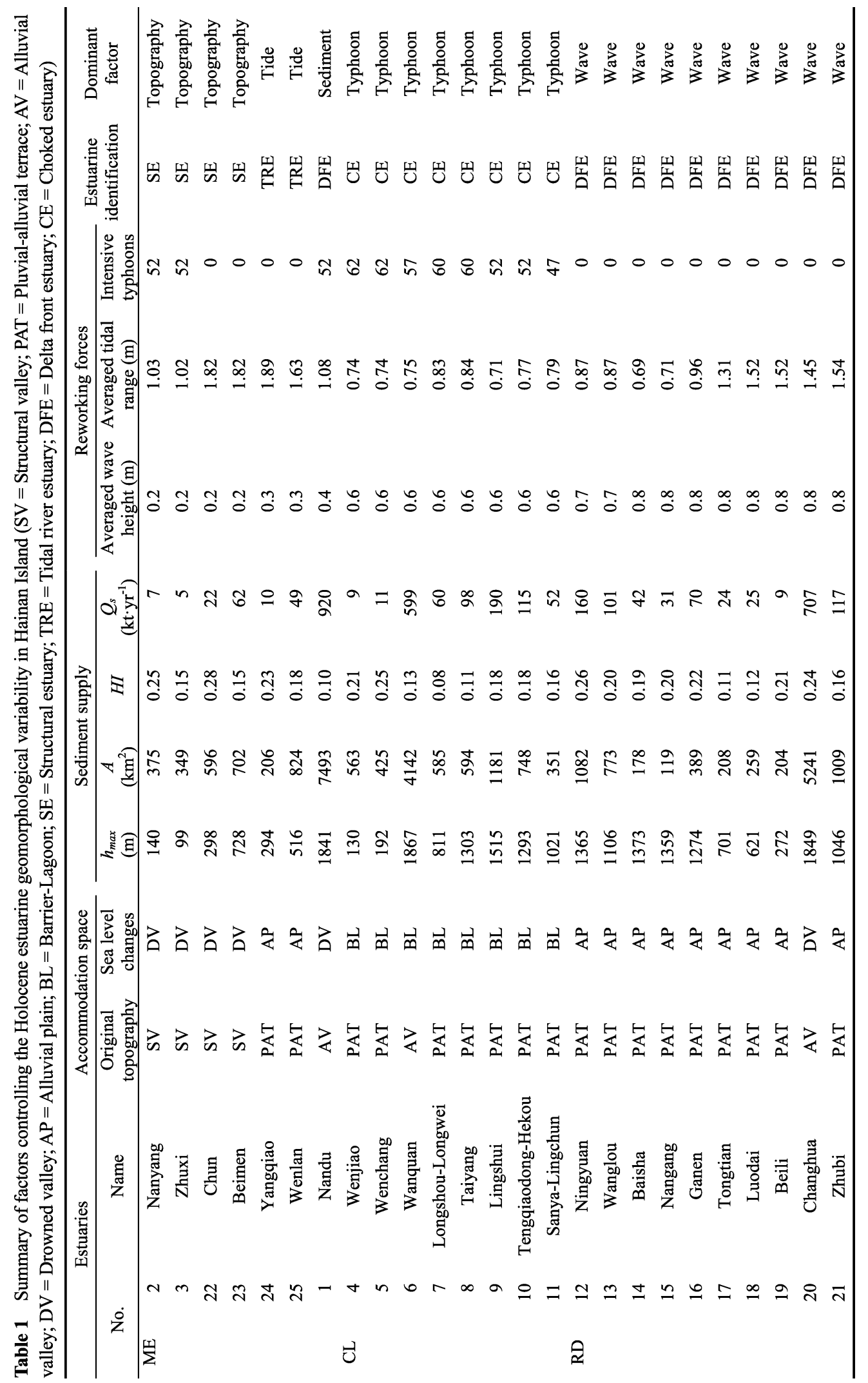


When the sediment supply is below the TSF, no delta will, or a river delta will suffer from wave-induced or flooding-induced erosion. For example, the TSF of the Changjiang River

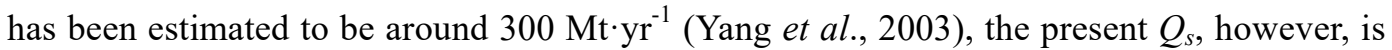
smaller than this value, so are under dramatic threat of coastal erosion and subaqueous delta retreat (Yang et al., 2011). In comparison, if the amount is larger than the TSF, the morphology of a delta is concerned with sediment size (Orton and Reading, 1993; Caldwell and Edmonds, 2014), cohesion (Edmonds and Slingerland, 2009) and the relative importance of delta-shaping processes (Wright and Coleman, 1972; Gao and Collins, 2014).

Due to the different order of magnitude of TSF, it can be inferred that significant differences of the geomorphological size will occur between those deltas developed from different kinds of accommodation space. In generally, the size of the accommodation space for DV estuaries in coastal Hainan are relative larger, and for AP estuaries are relative smaller, and for $\mathrm{BL}$ ones are in between. Combined with the bed reworking forcing, river deltas formed from the DVs will have the largest size (i.e. the Nandu River delta), and relative smaller size for the BLs, and in between for the APs (Figure 7). Similar landscapes have occurred in Asia estuaries, the area of the delta plains is of the order of $10^{3}-10^{4} \mathrm{~km}^{2}$ for large river deltas, such as the Ganges-Brahmaputra River delta and Changjiang River delta, which are in association with large drowned valley during mid-Holocene, whereas those alluvial plain ones are only in order of $10^{1}-10^{2} \mathrm{~km}^{2}$ (Li et al., 2018). Future works should focus on the process-product relationships between drainage basins and estuaries/deltas. Owing to the effects of changing the climate and frequent human activities, the water and sediment discharges entering the sea greatly changed, thereby exerting a significant impact on the development and evolvement of the estuarine/delta sedimentary systems.

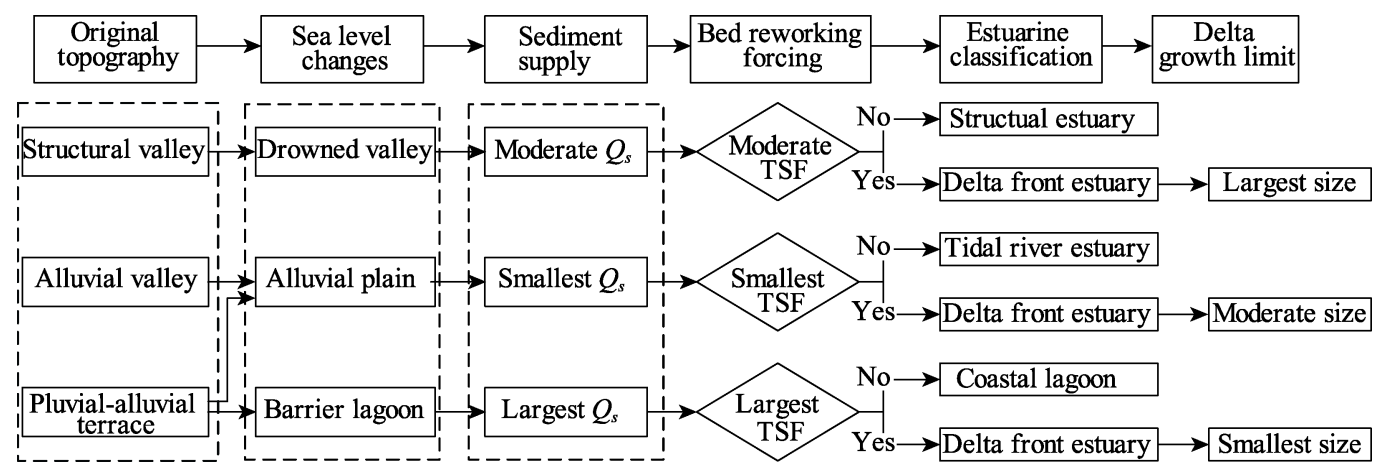

Figure 7 Flow chart for the Holocene estuarine geomorphological evolution in coastal Hainan

\section{Concluding remarks}

In the present study, the dominant factors controlling the geomorphological variability of estuaries in coastal Hainan Island and the threshold sediment flux (TSF) to form a river delta were investigated based on the big data method. Results indicated the 25 estuaries under consideration can be divided into three geomorphological zones, e.g. the northern mixed estuaries zone, the western river deltas zone, and the eastern coastal lagoons zone. The dominant factor for the former zone is original topography, or tide process, or sediment supply, while that of the secondary zone is wave process, and that of the last zone is typhoon 
process. In coastal Hainan, the order of magnitude for alluvial plain estuaries to form a river delta is the smallest $\left(10^{1} \mathrm{kt}^{\cdot} \mathrm{yr}^{-1}\right)$, for barrier lagoon ones is the largest $\left(>10^{2} \mathrm{kt}^{\prime} \mathrm{yr}^{-1}\right)$, and for drowned valley ones is in between $\left(10^{2} \mathrm{kt}^{\cdot} \mathrm{yr}^{-1}\right)$. The growth limit of those river deltas formed under the drowned valley estuaries will have the largest size, and the smallest size for the barrier lagoon estuaries, and in between for alluvial plain estuaries, further investigations are required to test this hypothesis.

\section{References}

Bates C C, 1953. Rational theory of delta formation. Aapg Bulletin, 37(9): 2119-2162.

Bianchi T S, Allison M A, 2009. Large-river delta-front estuaries as natural "Recorders" of global environmental change. Proceedings of the National Academy of Sciences, 106(20): 8085-8092.

Blum M D, Roberts H H, 2009. Drowning of the Mississippi Delta due to insufficient sediment supply and global sea-level rise. Nature Geoscience, 2(7): 488-491.

Caldwell R L, Edmonds D A, 2014. The effects of sediment properties on deltaic processes and morphologies: A numerical modeling study. Journal of Geophysical Research: Earth Surface, 119(5): 961-982.

Chen J S, Chen M, Xie G B, 1992. Comparative study on water chemistry between Hainan Island and Taiwan Island. Acta Geographica Sinica, 47(5): 403-409.

Committee of Data Compilation of Coastal Bays in China (CDCCBC), 1999. Compilation of Coastal Bays in China Vol.11: Coastal Bays of Hainan Province. Beijing: China Ocean Press, 1-426. (in Chinese)

Committee of Encyclopedia of Hainan (CEH), 1999. Encyclopedia of Hainan Island. Beijing: China Press for Encyclopedia, 1-893. (in Chinese)

Cukier K, Viktor M S, 2013. The rise of big data: How it's changing the way we think about the world. Foreign Affairs, 92(1): 28-40.

Davis J R A, Hayes M O, 1984. What is a wave-dominated coast? Marine Geology, 60(1): 313-329.

Dyer K R, 1995. Sediment Transport Processes in Estuaries. Developments in Sedimentology, 53: 423-449.

Edmonds D A, Slingerland R L, 2010. Significant effect of sediment cohesion on delta morphology. Nature Geoscience, 3(2): 105.

Eisma D, 1986. Flocculation and de-flocculation of suspended matter in estuaries. Netherlands Journal of Sea Research, 20(2/3): 183-199.

Foufoula-Georgiou E, Syvitski J, Paola C et al., 2013. International year of deltas 2013: A proposal. Eos, Transactions American Geophysical Union, 92(40): 340-341.

Gao S, 2007. Modeling the growth limit of the Changjiang Delta. Geomorphology, 85(3/4): 225-236.

Gao S, Collins M B, 2014. Holocene sedimentary systems on continental shelves. Marine Geology, 352(3): 268-294.

Gao S, Zhou L, Li G C et al., 2016. Processes and sedimentary records for Holocene coastal Environmental changes, Hainan Island: An overview. Quaternary Sciences, 36(1): 1-17. (in Chinese)

Giosan L, Syvitski J, Constantinescu S et al., 2014. Climate change: Protect the world's deltas. Nature, 516(7529): 31-33.

Hampton S E, Strasser C A, Tewksbury J J et al., 2013. Big data and the future of ecology. Frontiers in Ecology and the Environment, 11(3): 156-162.

Han G, Chu X, Xing Q et al., 2015. Effects of episodic flooding on the net ecosystem $\mathrm{CO}_{2}$ exchange of a supratidal wetland in the yellow river delta. Journal of Geophysical Research: Biogeosciences, 120(8): $1506-1520$.

He D Z, Zhang S L, 1985. The regional climate division of Hainan Island. Acta Geographica Sinica, 40(2): 169-178. (in Chinese)

Huang W P, 2017. Modelling the effects of typhoons on morphological changes in the Estuary of Beinan, Taiwan. Continental Shelf Research, 135: 1-13. 
Inman D L, Nordstrom C E, 1971. On the tectonic and morphologic classification of coasts. The Journal of Geology, 79(1): 1-21.

Kettner A J, Restrepo J D, Syvitski J P M, 2010. A spatial simulation experiment to replicate fluvial sediment fluxes within the Magdalena River Basin, Colombia. Journal of Geology, 118(4): 363-379.

Li C C, 1986. Geomorphic characteristics of the harbour-coasts in South China. Acta Geographica Sinica, 41(4): 311-320. (in Chinese)

Li G C, Gao S, Dai C, 2016. Geomorphological evolution of major catchment basins of Hainan Island, southern China. Quaternary Sciences, 36(1): 121-130. (in Chinese)

Li G C, Gao S, Gao J H, 2018. Modeling the growth limit of seven major Holocene river deltas in Asia. Marine Geology \& Quaternary Geology, 38(1): 11-22. (in Chinese)

Luo Z L, 1986. Recent coastal landforms in Hainan Island. Tropical Geography, 7(1): 65-75. (in Chinese)

Ma Z B, Xiao, J L, Zhao X T et al., 2003. Precise u-series dating of coral reefs from the South China Sea and the high sea level during the Holocene. Journal of Coastal Research, 19(2): 296-303.

Milliman J D, Farnsworth K L, 2013. River Discharge to the Coastal Ocean: A Global Synthesis. London: Cambridge University Press.

Milliman J D, Farnsworth K L, Albertin C S, 1999. Flux and fate of fluvial sediments leaving large islands in the East Indies. Journal of Sea Research, 41(1/2): 97-107.

Nienhuis J H, Ashton A D, Giosan L, 2015. What makes a delta wave-dominated? Geology, 43(6): 511-514.

Orton G J, Reading H G, 1993. Variability of deltaic processes in terms of sediment supply, with particular emphasis on grain size. Sedimentology, 40(3): 475-512.

Perillo G M, 1995. Definitions and geomorphologic classifications of estuaries. Developments in Sedimentology, 53: $17-47$.

Pike R J, Wilson S E, 1971. Elevation-relief ratio, hypsometric integral, and geomorphic area-altitude analysis. Geological Society of America Bulletin, 82(4): 1079-1083.

Schmidt C, 2015. Alarm over a sinking delta. Science, 348(6237): 845-846.

Shanghai Typhoon Institute (STI), 2006. Climatological Atlas for Tropical Cyclones Affecting China (1951-2000). Beijing: Science Press, 177. (in Chinese)

Sloss L L, 1963. Sequences in the cratonic interior of North America. Geological Society of America Bulletin, 74: 93-113.

Stanley D J, Warne A G, 1994. Worldwide Initiation of Holocene marine deltas by deceleration of sea-level rise. Science, 265(5169): 228-231.

Statistical Bureau of Hainan Province, 1994-2011. Statistical Yearbook of Hainan Province. Statistical Publishing House, Beijing. (in Chinese) (Note: The "Statistical Yearbook of Hainan Province" has been published once a year since 1994 and, to avoid tedious and lengthy listing of references in this article, a combination for the period of 1994-2011 is adopted to have a single citation in the text as well as in the Figure legends).

Strahler A N, 1952. Hypsometric area-altitude analysis of erosional topography. Geological Society of America Bulletin, 63(11): 1117.

Syvitski J P M, Milliman J D, 2007. Geology, geography, and human's battle for dominance over the delivery of fluvial sediment to the coastal ocean. Journal of Geology, 115(1): 1-19.

Tu J Y, Gao S, Zhou L et al., 2016. Return periods and spatial-temporal distribution patterns of typhoons affecting in eastern Hainan Island. Quaternary Sciences, 36(1): 184-195. (in Chinese)

Vail P R, Mitchum R M, Todd R G et al., 1977. Seismic stratigraphy and global changes of sea level. In: Payton C E (ed.). Seismic Stratigraphy-Applications to Hydrocarbon Exploration. American Association of Petroleum Geologists Memoir, 26: 49-212.

Wang B C, Chen S L, Gong W P et al., 2006. Formation and Evolution of Embayment Coast of Hainan Island. Beijing: China Ocean Press, 1-214. (in Chinese)

Wang W J, 1999. Sea level change and development course of barrier lagoons along coast of western Guangdong since middle Holocene. Tropical Oceanology, 18(3): 32-37. (in Chinese)

Wang W J, Jin Z M, Bao Q S, 1983. Characteristic of natural conditions and the construction of ports in the 
coastal areas of Hainan Island. Tropical Geography, 3(3): 8-13. (in Chinese)

Wang X, Ma D, Jiang D, 1991. Geology of Hainan Island (II): Tectonic Geology. Beijing: Geological Press, 1-106. (in Chinese)

Wang Y, Peter M I, Zhu D et al., 2001. Coastal plain evolution in southern Hainan Island, China. Chinese Science Bulletin, 46(1): 90-96.

Wang Y, Zhou L F, 1990. The volcanic coast in the area of northwest Hainan Island. Acta Geographica Sinica, 50(3): 321-330. (in Chinese)

Wang Y P, Shi B, Zhang L et al., 2017. Assessing the vulnerability of changing coasts, Hainan Island, China. Acta Oceanologica Sinica, 36(4): 114-120.

Wright L D, Coleman J M, 1972. River delta morphology: Wave climate and the role of the subaqueous profile. Science, 176(4032): 282-284.

Xia X M, 2015. Status of Marine Resources and Environment of Hainan Island. Beijing: China Ocean Press, 1-27. (in Chinese)

Xu G, Guo Q, Niu S et al., 2013. Research on climate change characteristics of different regions in Hainan Island in the last 50 years. Journal of Natural Resources, 28: 799-810.

Yang S L, Milliman J D, Li P et al., 2011. 50,000 dams later: Erosion of the Yangtze River and its delta. Global and Planetary Change, 75(1): 14-20.

Yang S L, Zhu J, Zhao Q, 2003. A preliminary study on the influence of Changjiang River sediment supply on subaqueous delta. Acta Oceanologica Sinica, 25(5): 83-91. (in Chinese)

Yang Z H, Jia J J, Wang X K et al., 2013. Characteristics and variations of water and sediment fluxes into the sea of the top three rivers of Hainan in recent 50 years. Marine Science Bulletin, 32(1): 92-99. (in Chinese)

Yu Q, Wang Y, Gao J et al., 2014. Turbidity maximum formation in a well-mixed macrotidal estuary: The role of tidal pumping. Journal of Geophysical Research: Oceans, 119(11): 7705-7724.

Yuan J P, Yu L S, Deng Y Q et al., 2006. Geomorphologic division and classification of Hainan Island. Natural Science Journal of Hainan University, 24(4): 364-370. (in Chinese)

Zhang J, Wang D R, Jennerjahn T et al., 2013. Land-sea interactions at the east coast of Hainan Island, South China Sea: A synthesis. Continental Shelf Research, 57(1): 132-142.

Zhang Z Y, Liu R H, 1987. The Holocene along the coast of Hainan Island. Scientia Geographica Sinica, 7(2): $129-138$.

Zhong H, van Gelder P, van Overloop P et al., 2014. Application of a fast stochastic storm surge model on estimating the high water level frequency in the lower Rhine delta. Natural Hazards, 73(2): 743-759.

Zhou L, Gao S, Yang Y et al., 2017. Typhoon events recorded in coastal lagoon deposits, southeastern Hainan Island. Acta Oceanologica Sinica, 36(4): 37-45. 